\title{
Faktor Keberhasilan Program Pengembangan Kewirausahaan Mahasiswa Universitas Muria Kudus
}

\author{
${ }^{1}$ Nuraeningsih ${ }^{*},{ }^{2}$ Mamik Indaryani, ${ }^{1}$ Rusiana \\ ${ }^{1}$ Pendidikan Bahasa Inggis, Fakultas Keguruan dan Ilmu Pendidikan, Universitas Muria Kudus, Kudus, Indonesia \\ ${ }^{2}$ Manajemen, Fakultas Ekonomi dan Bisnis, Universitas Muria Kudus, Kudus, Indonesia
}

\begin{tabular}{llll} 
& \multicolumn{2}{c}{$*$ Corresponding Author } & \\
& \multicolumn{2}{c}{ E-mail: $\underline{\text { nuraeningsih@umk.ac.id }}$} & \\
Received: & Revised: & Accepted: & Published: \\
27 September 2021 & 24 October 2021 & 17 November 2021 & 24 November 2021
\end{tabular}

\begin{abstract}
Abstrak
Pemerintah melalui DPRM Ristekdikti mendorong perguruan tinggi untuk menumbuhkembangkan jiwa wirausaha mahasiswa. Hal ini sangat relevan dengan tagline Universitas Muria Kudus (UMK) yang mengusung motto "Santun, Cerdas dan Berjiwa Wirausaha" sehingga diharapkan lulusan UMK nantinya mandiri menciptakan lapangan kerja sendiri. PPK ini dapat menyiapkan mahasiswa agar mandiri secara finansial sebelum mereka lulus, sehingga tidak bergantung pada pekerjaan - pekerjaan yang disediakan oleh pemerintah maupun dunia industri. Tujuan dari program PPK adalah menghasilkan wirausahawan baru. Pada tahun 2019 terwujud 5 usaha baru yang dijalankan oleh 20 mahasiswa dan alumni dari prodi PBI, Manajemen Bisnis, Teknik Mesin dan Agroteknologi. Metode pelaksanaan kegiatan ini menggunakan teknik coaching \& mentoring. Usaha - usaha yang dirintis oleh tenant tersebut adalah budidaya adenium, budidaya jamur tiram, angkringan kopi SEKOPPI, angkringan sushi dan steak, serta sablon. Keberhasilan program ini dipengaruhi oleh banyak faktor, baik faktor pendamping dalam hal ini tim pengabdi maupun faktor mahasiswa. Faktor mahasiswa diantaranya adanya spirit yang lahir dari lingkungan keluarga yang juga memiliki usaha, transformasi nilai yang dilakukan secara akumulatif dalam keluarga dan lingkungan yang mendukung serta adanya bakat yang memungkinkan mahasiswa mudah menerima motivasi untuk melakukan kegiatan yang berorientasi pada munculnya kreativitas dan atau inovasi sebagai ciri utama wirausaha.
\end{abstract}

Kata kunci: faktor keberhasilan; wirausaha; mahasiswa

\begin{abstract}
Entrepreneurship Development Program (PPK) issued by the Ristekdikti DPRM offers more opportunities for the academic community in higher education to foster entrepreneurial spirit for students in particular. This is very relevant to Universitas Muria Kudus (UMK)'s tagline, "Polite, smart and entrepreneurial". UMK graduates are expected to independently create their own jobs, therefore they will not depend on jobs provided by the government or the industry. PPK aims at creating students to be financially independent as entrepreneurs. In the first year, 2019 PPK program yielded 5 new business tenants among 20 tenants consisting students and alumni of English Education Department, Business Management, Agriculture, and Mechanical Engineering department. To run the program, the methods used were coaching and mentoring. The businesses which are established by the tenants are Adenium farm, oyster mushroom farm, SEKOPPI coffee shop, sushi and steak, and screen printing. The success of this program is influenced by many factors, both the accompanying factors in this case the service team and student factors. Student factors include the presence of a spirit that is born from a family environment that also has a business, the transformation of values carried out accumulatively in the family and a supportive environment and the talent that
\end{abstract}




\begin{abstract}
allows students to easily receive motivation to carry out activities oriented to the emergence of creativity and or innovation as the main characteristic of entrepreneurship. The program which is arranged must be adjusted to the students' characteristics in the millennium era by maximizing the use of information technology and implemented with an appropriate approach. This conclusion was obtained from observations during the program.
\end{abstract}

Keywords: success factors; entrepreneurship; students

\title{
PENDAHULUAN
}

Pengangguran terdidik yang semakin meningkat sangat memprihatinkan. Masalah ini mendorong Perguruan Tinggi untuk menyepakati program pengembangan wirausaha yang dicanangkan untuk menghasilkan wirausaha baru. Wirausaha baru berbasis lulusan perguruan tinggi merupakan target yang ideal, di mana mahasiswa didorong untuk menjadi creator dan innovator. Kreativitas dan Inovasi menjadi inti dari industri kreatif.

Wirausaha baru dari kalangan perguruan tinggi menjadi dinamisator dan trigger pertumbuhan ekonomi yang bersumber dari sumberdaya kreatif non sumberdaya alam. Secara teori Indonesia akan menjadi pemain ekonomi di era millennium ketika jumlah wirausaha mencapai $20 \%$. Saat ini wirausaha di Indonesia masih berkisar pada angka $1 \%$ dan hal tersebut masih sangat tertinggal dibanding negara-negara Asia lainnya, seperti Malaysia, Thailand, Philipina dan Singapura yang telah mencapai kisaran lebih dari 5 \% (Siregar, 2018).

Permasalahannya adalah bahwa masyarakat Indonesia telah memiliki daya saing alamiah dalam industri berbasis budaya, seperti kerajinan dan produk non-migas lainnya yang menyebabkan peningkatannya lambat. Kreativitas dan inovasi yang ada harus didukung oleh informasi dan teknologi yang akan mendukung kreativitas dalam promosi dan pemasarannya. Teknologi produksi tidak kalah pentingnya untuk menjamin keberlanjutan persediaan produk, baik barang dan jasa untuk keberlanjutan dan terobosan dalam keberlanjutan bisnisnya secara global.

Munculnya wirausaha muda dari kalangan perguruan tinggi diharapkan mengisi kekosongan untuk mengejar ketertinggalan dalam penggunaan IT dalam bisnis, dan inovasi produk maupun pasar. Permasalahan yang lain muncul, karena kecepatan sarana dan prasarana, teknologi berbasis internet belum merata dalam ketersediaan maupun kompetensi dikalangan para pelaku usaha dan wirausaha. Salah satu solusi adalah mendorong sebanyak-banyaknya mahasiswa menjadi wirausaha melalui pengembangan wirausaha mahasiswa.

Tantangan untuk mewujudkannya bukan hanya dihadapi oleh para mahasiswa yang menganggap bahwa wirausaha belum menjadi pilihan utama setelah lulus. Menurut Gaffar \& Hendrayati (2019), sebagian besar pengangguran yang ada di Indonesia adalah lulusan Diploma 3 dan sarjana karena mindset mereka masih terpaku untuk menjadi karyawan, bukan menjadi pemilik usaha atau wirausahawan. Tentu ini dipengaruhi oleh banyak faktor seperti image sosial serta pandangan masyarakat bahwa seorang sarjana dipandang punya strata sosial yang tinggi jika ia mampu bekerja dan menduduki jabatan di suatu lembaga terutama milik pemerintah. Selain itu juga dipengaruhi oleh pendidikan dalam keluarga, di mana orang tua biasanya menanamkan nilainilai tertentu terkait dengan jenis pekerjaan yang sama atau mirip dengan pekerjaan orang tua.

Kendala lain dalam melahirkan wirausaha mahasiswa adalah kesenjangan kemampuan para pengabdi dosen pendamping yang memiliki keterbatasan dalam mendampingi dari sisi kapasitas, kompetensi dan fokus tuntutan tri darma perguruan tinggi yang kurang seimbang dalam realitasnya. Kompetensi para dosen pendamping disebabkan adanya lag alamiah karena perbedaan generasi. Bahwa setiap generasi memiliki karakteristiknya sendiri, mempengaruhi kesesuaian metode pembelajaran dan pendekatan yang digunakan. Di sinilah diharapkan perguruan tinggi untuk lebih memberikan perhatian kepada tenaga akademik dengan kemampuan 
dan pengetahuan kewirausahaan. Pelatihan, seminar, serta magang di industri dapat menjadi penyelesaian kurangnya kapasitas dosen pendamping.

Wirausaha sangat berkaitan erat dengan inovasi dan kreasi. Hisrich \& Peters (1998), mendefinisikan kewirausahaan sebagai suatu proses menciptakan sesuatu yang baru dan mengambil segala risiko dan imbalannya. Sedangkan wirausaha adalah seorang innovator yaitu seseorang yang mengembangkan sesuatu yang unik dan berbeda. Definisi tersebut memberikan gambaran bahwa wirausaha dan kewirausahaan yang dimiliki seseorang akan mendatangkan keuntungan berupa imbalan, disamping risiko yang harus diperhitungkan. Minimalisasi risiko akan mendatangkan optimasi imbalan, jika skill dan spirit berjalan seiring. Apalagi jika keduanya terbangun sejak usia muda, dan dikembangkan dengan sengaja dalam suatu program, di kalangan mahasiswa dalam perguruan tinggi.

Universitas Muria Kudus sebagai Perguruan Tinggi dengan tagline santun, cerdas, dan berjiwa wirausaha telah melakukan upaya-upaya di mana salah satunya adalah mengintegrasikan ketiga hal tersebut dalam kurikulumnya. Berjiwa wirausaha memiliki makna yang berbeda dengan berwirausaha, namun dengan pengalaman belajar yang sistematis dan terarah maka dapat dipastikan lulusan-lulusan UMK adalah lulusan yang mempunyai pengalaman dan siap berwirausaha.

Dalam berwirausaha, selain skill yang bersifat hard juga sangat penting memperhatikan program yang diarahkan untuk mengembangkan soft skill. Hard skill dapat berupa keterampilan motorik dan juga keterampilan yang terkait dengan keterlatihan otot (muscle), sementara soft skill memperkuat karakter yang dicerminkan dalam perilaku keseharian mahasiswa dalam bersosialisasi dengan masyarakat dan lingkungan sekitar (Krisdayanti \& Trisiana, 2019). Karakter yang kuat akan membentuk jiwa wirausaha yang kuat pula karena keberanian mengambil risiko dalam berbisnis. Perpaduan soft skill dan hard skill akan sangat menentukan keberhasilan wirausaha yang dijalankan mahasiswa. Penyusunan program yang sesuai dan berorientasi kemampuan yang hard dan soft, diharapkan dapat mendorong sikap dan perilaku mahasiswa serta menumbuhkan minat mahasiswa untuk menjadi wirausaha sebagai pekerjaan utama. Wirausaha sebagai pekerjaan akan diekspresikan dalam aktvitas bisnis. Tetapi wirausaha sebagai spirit akan menjadi kunci sukses mahasiswa di masa depan di manapun pada akhirnya mahasiswa sendiri yang memilih profesi yang diinginkannya.

Salah satu program pengembangan wirausaha mahasiswa adalah hibah Kemenristek Dikti skema Pengembangan Kewirausahaan Mahasiswa. Di samping program pendamping dan mahasiswa sebagai suatu sinergi, menumbuhkan minat mahasiswa harus dilakukan secara terus menerus. Untuk itu harus didukung oleh lingkungan yang kondusif, dan terus menghidupi spirit yang telah terbangun dalam diri mahasiswa. Lingkungan keluarga atau lingkungan pergaulan memegang peran yang sangat penting. Sesuai dengan sifat dan karakter lingkungan yang cocok dan mendukung, secara terakumulasi akan terus melakukan transformasi nilai kepada mahasiswa yang telah di intervensi program. Sehingga mahasiswa dapat melanjutkannya dengan beraktivitas sebagai ekspresi seorang wirausaha, dalam bentuk usaha kreatif yang diminatinya.

Keluarga yang memiliki nilai dan norma serta spirit wirausaha biasanya akan lebih banyak berpotensi melahirkan wirausaha secara alamiah. Seperti yang ditulis oleh Suryaningtyas (2004), lingkungan dibedakan menjadi dua, yakni lingkungan fisik dan lingkungan sosial. Lingkungan fisik adalah alam di mana manusia berada, sedangkan lingkungan sosial merupakan lingkungan masyarakat berinteraksi dan melakukan kegiatan sosial. Diketahui bersama bahwa banyak penduduk di kabupaten Kudus yang berprofesi sebagai pedagang maupun wirausahawan. Hal ini erat kaitannya dengan nilai dan ajaran Sunan Kudus yang terkenal dengan gusjigang yang merupakan kependekan dari bagus ngaji dan dagang, Bagus memiliki arti berperilaku baik, sementara ngaji mengandung arti memiliki semangat dan kemauan untuk belajar ilmu agama. Nilai dagang dapat dimaknai sebagai semangat berwirausaha atau mendapatkan kemandirian finansial dengan menjalankan usaha sendiri. Nilai kearifan lokal ini masih kuat dianut oleh 
sebagian besar masyarakat Kudus. Hal ini tentu memberikan pengaruh yang positif dalam pemgembangan semangat dan jiwa kewirausahaan.

Dengan dukungan program yang tepat maka mahasiswa akan mendapatkan habitat yang sesuai untuk bertumbuh dan mengembangkan bakatnya yang didasari oleh nilai kearifan lokal yang terdapat di wilayah tempat tinggal sehingga program tersebut diharapkan memberikan ruang kepada mahasiswa agar dapat berekspresi dan berkembang di lingkungan yang tepat. Pemilihan lingkungan sebagai tempat tinggal dan bergaul akan mendukung percepatan dan suburnya benih, bakat, semangat dan spirit wirausaha mahasiswa yang pada akhirnya pada saatnya berbuah sebagai imbalan, baik berupa benefit maupun finansial yang akan memberikan dampak positif tidak hanya kepada mahasiswa, tetapi juga masyarakat serta lembaga di mana mahasiswa bernaung.

\section{METODE}

Program Pengembangan Kewirausahaan FKIP UMK ini diawali dengan rekrutmen peserta yang dipublikasikan di media sosial FKIP maupun website FKIP. Mahasiswa dan alumni yang berminat kemudian mendaftar dengan mengisi form untuk selanjutnya mengikuti seleksi dan wawancara. Seleksi awal menyaring untuk mendapatkan pendaftar yang benar-benar tertarik dengan program wirausaha. Jumlah tenant yang terseleksi adalah 20 mahasiswa dan alumni dari berbagai program studi. Tahapan kegiatan berikutnya mencakup pelatihan/workshop, coaching penentuan ide bisnis, eksekusi bisnis, pendampingan bisnis, dan evaluasi. Pelatihan atau workshop yang diselenggarakan yaitu Workshop Orientasi Bisnis, Motivation on Social Business: Money or Impact?, Business Plan, Bisnis Online, Pengelolaan Usaha, Customer Targeting and Marketing, Product Labelling, serta Pelatihan Bahasa Inggris (Englishpreneurship). Pemateri pelatihan dan workshop ditentukan berdasarkan kompetensi dan kepakaran yang terdiri dari praktisi kewirausahaan serta tim dosen PPK itu sendiri. Penentuan ide bisnis dilakukan dengan pengajuan bisnis plan oleh mahasiswa dan masukan dari mahasiswa lain serta tim dosen, di mana sebelumnya mereka sudah mengikuti pelatihan penyusunan proposal rencana bisnis. Setelah jenis usaha sudah mantap dipilih, eksekusi bisnis dilakukan. Sekarang ini masih berjalan proses pendampingan bisnis. Evaluasi akan dilakukan secara regular untuk mengetahui lebih dini masalah dan tantangan yang muncul serta ditemukan cara yang tepat untuk menanganinya. Coaching sangat dibutuhkan bagi para pelaku usaha baru (Fitrihana et al., 2014). Selain itu, perlu dilakukan mentoring dan coaching (Popp \& Holt, 2013) untuk mempertajam kemampuan para tenant. Mentoring adalah proses berbagi pengalaman dan pengetahuan dari seorang yang sudah berpengalaman kepada seseorang yang yang ingin belajar di bidang tersebut. Mentoring dilakukan dengan membimbing, pelatihan dan memberi saran.

Coaching memiliki banyak manfaat bagi mahasiswa pelaku usaha baru, di antaranya:

1. Melalui pertanyaan-pertanyaan coach, coachee mampu mengungkap apa yang menjadi tantangan.

2. Coachee dapat menemukan tantangan yang terjadi bahkan tantangan pribadi yang kemungkinan menjadi halangan terbesar bagi coachee untuk maju.

3. Coachee akan memiliki beberapa alternatif penyelesaian. Coach kemudian menuntun coachee menemukan mana alternatif terbaik yang dapat menjadi solusi tantangan yang dihadapi coachee.

4. Coachee akan membuat action plan dan coach akan bertemu lagi dengan coachee untuk membahas atau mengevaluasi pencapaian coachee

5. Setelah ada pertanyaan yang "menggugah" maka biasanya coachee akan aktif untuk 
mencari solusi. Coachee memiliki beberapa alternatif penyelesaian masalah maka coach harus menuntun menemukan alternatif terbaik yang dapat menjadi solusi masalah tersebut.

Dalam pelaksanaan program, tim dosen melakukan pengamatan dan juga wawancara kepada para tenant untuk bisa mendapatkan data faktor-faktor yang mempengaruhi keberhasilan program pengembangan kewirausahaan mahasiswa. Koordinasi maupun kunjungan langsung ke rumah atau lokasi usaha tenant dilakukan oleh tim PPK secara berkala untuk mengetahui perkembangan usaha tenant serta identifikasi hambatan yang dihadapi tenant agar dapat dicarikan pemecahannya. Evaluasi diselenggarakan secara periodik sebagai upaya pengukuran efektivitas program baik yang bersifat klasikal yang mencakup keseluruhan tenant, maupun secara individual, di mana setiap mahasiswa memiliki tugas dan tanggungjawab yang sama.

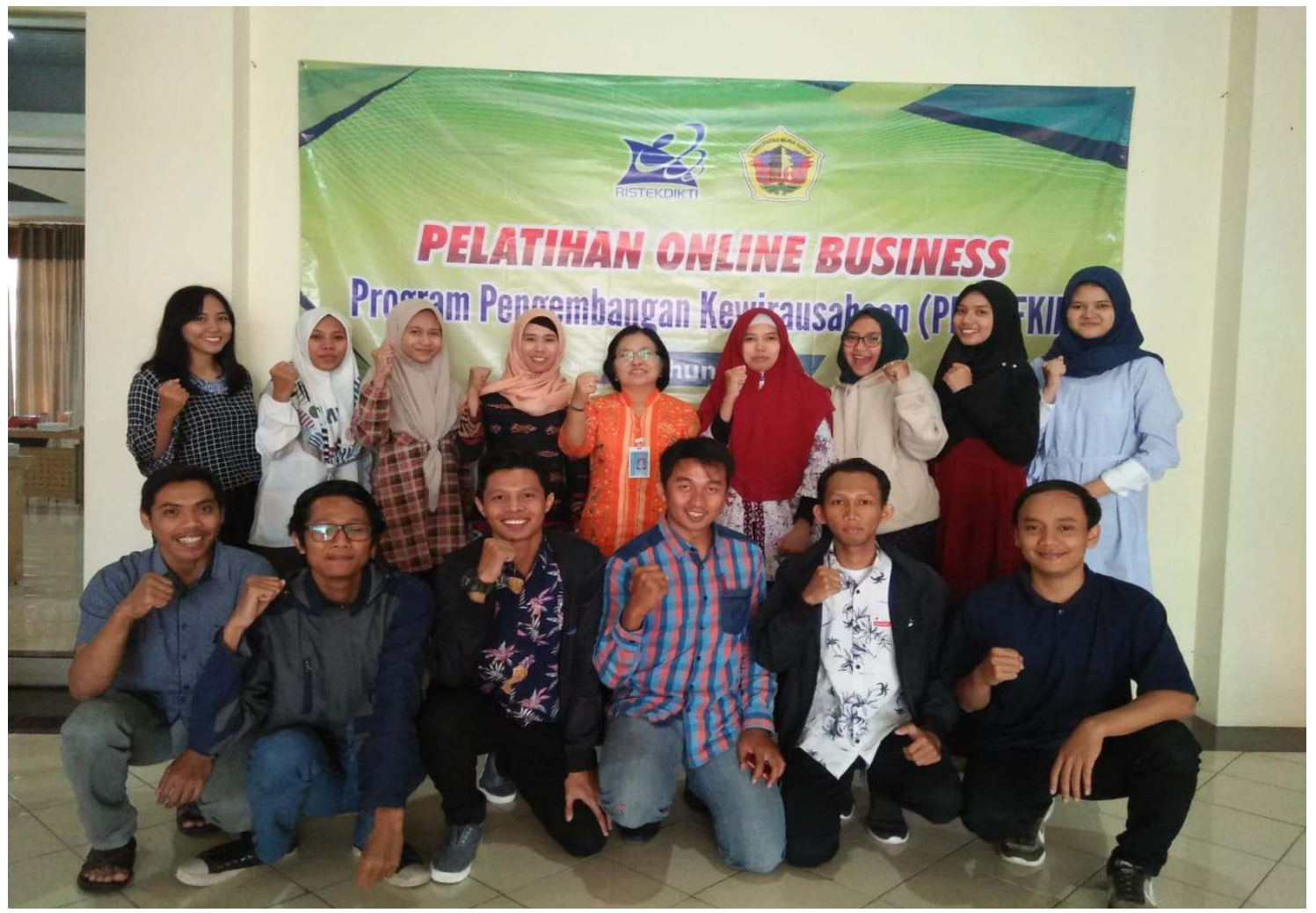

Gambar 1. Pelatihan Online Business

\section{HASIL DAN PEMBAHASAN}

Dari sejumlah 20 mahasiswa yang direkrut pada awal program, hanya 50\% mahasiswa yang bertahan dan mempunyai komitmen untuk berwirausaha sesuai dengan bidang minat dan keahliannya. 10 mahasiswa dengan 5 usaha baru yang berbeda tersebut mempunyai kemampuan mengelola sumber daya yang dimiliki diri sendiri dan kompetensi yang kuat. Sumber daya manusia merupakan faktor yang sangat penting dalam menentukan keberhasilan wirausaha (Gaffar \& Hendrayati, 2019; Suryaningtyas, 2004).

Selain itu, semangat dan motivasi yang tinggi yang ditunjukkan dengan keterlibatan para tenant dalam setiap kegiatan yang dilakukan oleh Tim PPK. Motivasi dan keinginan kuat untuk mencapai tujuan adalah salah satu karakter yang dimiliki wirausahawan (Meredith, 2002). Tingginya motivasi yang dimiliki tenant menimbulkan kepercayaan diri yang kuat pula bahwa mereka mampu untuk melaksanakan tugas mereka dengan baik. Hal ini sesuai dengan pendapat Yanti (2019) bahwa semakin tinggi kepercayaan diri terhadap kemampuan diri, semakin kuat 
keinginan untuk menjadi wirausaha. Motivasi tersebut tampak dari partisipasi mahasiswa mengikuti setiap tahapan kegiatan yang ditentukan tim. Kehadiran dan keaktifan mereka semakin memperkuat personal belief bahwa mereka mempunyai kompetensi berwirausaha.

Ternyata motivasi diri yang kuat tersebut memang didukung juga oleh lingkungan keluarga. Hal ini sesuai dengan hasil penelitian yang dilakukan oleh (Fatharani et al., 2019) yang menunjukkan bahwa lingkungan keluarga memberikan pengaruh yang signifikan terhadap motivasi berwirausaha para mahasiswa. Semakin tinggi dorongan yang dicurahkan keluarga, semakin tinggi pula motivasi berwirausaha para mahasiswa. Tenant dengan jenis usaha adenium, jamur tiram, sushi dan steak ternyata berasal dari keluarga yang sangat suportif dan memberikan motivasi kepada mereka untuk menjalankan usaha. Tidak hanya dukungan secara materi yang keluarga tunjukkan, namun juga saran, pendapat serta semangat yang mereka sampaikan kepada tenant agar senantiasa terjaga komitmennya menjalankan usaha yang baru mereka rintis. Beberapa keluarga dari mahasiswa juga telah menjalankan usaha dimana mereka telah mempunyai pengalaman dan juga secara langsung maupun tidak langsung jiwa dan semangat berwirausaha sudah ada. Artinya bahwa keluarga atau orang tua dengan jenis pekerjaan wirausaha akan cenderung menurunkan minat yang sama terhadap anaknya untuk menjadi seorang wirausahawan juga (Fahlia \& Mulyani, 2018). Hal ini mengandung asumsi dan perlu dikaji lebih dalam melalui penelitian bahwa semakin banyak orang tua wirausaha, semakin banyak pula anak muda yang menggeluti dunia wirausaha sebagai ladang penghidupan mereka.

Faktor lingkungan keluarga berperan menumbuhkan jiwa wirausaha di mana seorang anak mengamati dan mengalami secara langsung usaha yang dijalankan orang tua atau keluarganya (Suryana, 2013). Terlebih lagi orangtua sangat mendukung anaknya yang mau mengembangkan usaha secara mandiri. Orang tua yang mengajari berwirausaha serta melibatkan anaknya dalam kegiatan ekonomi yang mereka jalankan, memberikan pengalaman nyata (experiencing learning) yang akan mendukung pembelajaran pendidikan kewirausahaan di kampus. Orang tua nonwirausaha yang memberikan kesempatan dan kepercayaan kepada anaknya untuk menempa diri melalui kegiatan kewirausahaan merupakan hal yang sangat positif karena dengan dukungan orang tua mahasiswa akan merasa nyaman dan bebas untuk mewujudkan ide-ide kreatif yang membangun konsistensi mereka dan menjadikan mereka bertahan tetap melangsungkan usaha mereka. Dengan adanya program pengembangan kewirausahaan maka kesempatan bagi para mahasiswa untuk mengaktualisasikan diri dalam berwirausaha.

Faktor-faktor keberhasilan dalam Program Pengembangan wirausaha adalah faktor tim dosen dan juga faktor mahasiswa dimana keduanya harus bersinergi dan menjalankan kapasitasnya masing-masing hingga terwujudnya usaha/bisnis baru. Penentuan tujuan yang jelas di awal kegiatan, menuntun kedua pihak untuk menjalankan peran dan tanggung jawab masingmasing. Tim dosen secara reguler dan berkesinambungan melakukan pendampingan agar tenant lebih mantap dan percaya diri dalam mengembangkan usahanya. Koordinasi dan mentoring secara regular dilakukan sebagai media komunikasi antara tim dosen PPK dan mahasiswa. Hal ini sangat penting karena mentoring tidak berfungsi secara optimal ketika tenant tidak terbuka untuk menyampaikan permasalahan maupun kendala yang dihadapi selama menjalankan usaha. Dari tim PPK sendiri, kejelasan deskripsi tugas masing-masing dosen serta tanggungjawab dan komitmen melaksanakan program PPK sebaik-baiknya membuat tahapan kegiatan menjadi lebih mudah dilalui. Komitmen tim dosen untuk menjalankan program secara maksimal ditunjukkan secara nyata. Hal tersebut menjadikan salah satu faktor keberhasilan program PPK. Komitmen yang kuat merupakan salah satu penentu keberhasilan suatu program (Suarmawan et al., 2015).

Faktor mahasiswa yaitu motivasi yang tinggi dari diri sendiri, serta support system yang baik dari sesama mahasiswa/tenant dan juga keluarga. Dengan saling memotivasi dan juga sharing dari sesama tenant akan menguatkan dan menumbuhkan ide-ide kreatif lain untuk mengembangkan usaha. Forum komunikasi antar tenant terbukti efektif memperkuat networking dan kerjasama yang saling menguntungkan. Persamaan visi dan misi untuk maju bersama perlu 
Indonesian Journal of Community Services

Volume 3, No. 2, November 2021

http://jurnal.unissula.ac.id/index.php/ijocs

DOI: http://dx.doi.org/10.30659/ijocs.3.2.126-134

terus dipupuk agar ikatan korps dan solidaritas antar mahasiswa tetap kokoh. Dukungan keluarga juga sangat penting untuk menjamin keberlanjutan program wirausaha mahasiswa karena keluarga merupakan tempat bermula setiap mahasiswa, bertumbuh serta berkembang yang bersinergi dengan lembaga pendidikan tinggi serta masyarakat.

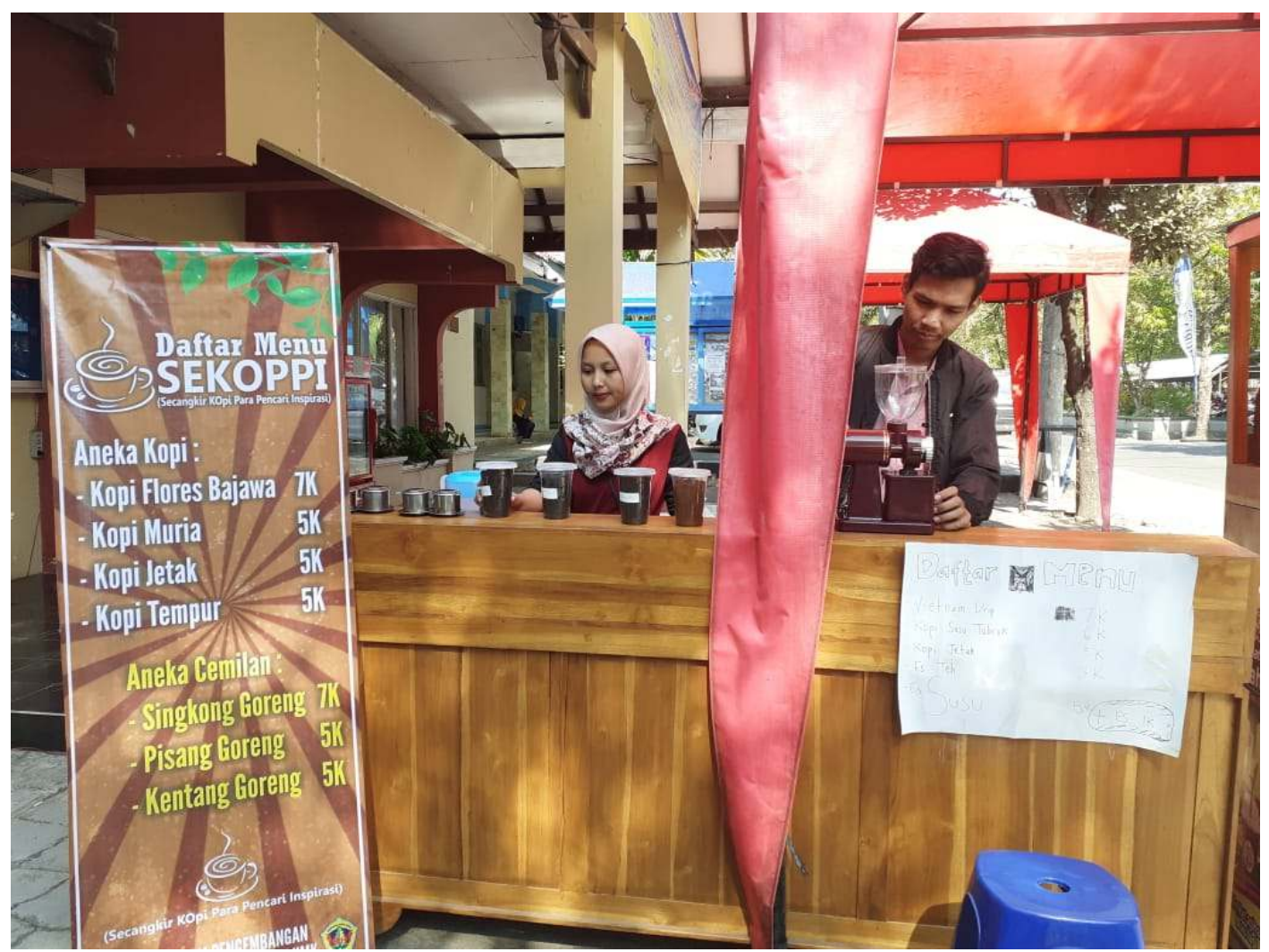

Gambar 2. Aktivitas wirausaha tenant.

\section{KESIMPULAN}

Program pengembangan wirausaha mahasiswa sangat strategis sebagai pendidikan dan pembelajaran wirausaha, baik dalam aspek skill dan spirit. Institusi perguruan tinggi yang memiliki komitmen menyelenggarakan program dan didukung oleh Kemenristek Dikti, menjadi sinergi yang berkelanjutan dan dapat menjawab keprihatinan lahirnya mahasiswa yang hanya akan menjadi pekerja, tetapi melahirkan wirausaha baru yang kompeten dan mumpuni.

Secara nasional, pendidikan tinggi sepakat untuk menjadi media persemaian lahirnya startup yang akan tumbuh menjadi wirausaha muda yang kuat dan tahan menghadapi tantangan jaman dalam persaingan yang semakin ketat. Kreativitas dan inovasi akan memungkinkan menjadi masyarakat yang kreatif dan tidak terkalahkan. Sinergi program dan komitmen untuk selalu menjadi mediator dengan para alumni yang telah berhasil menjadi nilai tambah mahasiswa dan juga menjadi inovator dalam membangun nilai tambah bagi produk, barang dan jasa yang akan menjadi unggulan komoditas Indonesia pada akhirnya. Program pengembangan wirausaha di Perguruan Tinggi secara berkelanjutan akan dapat menjadi solusi terhadap permasalahan pengangguran terdidik di masa depan. 


\section{UCAPAN TERIMA KASIH}

Tim penulis mengucapkan terimakasih kepada DPRM Kemenristek Dikti atas pendanaan dan kesempatan untuk melaksanakan kegiatan hibah PKM skim PPK tahun ke-1 tahun 2019 di FKIP UMK. Tak lupa penghargaan dan apresiasi yang tinggi kepada segenap pimpinan Universitas Muria Kudus, Rektor UMK Dr. Suparnyo, SH, MS, kepala LPPM Dr. Mamik Indaryani, MSi., Ka.bag. Pengabdian Pada Masyarakat Ir. Sodiq EKo Ariyanto, MP atas bimbingan, saran serta dukungan yang diberikan kepada tim selama program berlangsung. Terimakasih pula kami sampaikan kepada semua tenant PPK FKIP UMK tahun ke-1 dan seluruh anggota tim PPK atas partisipasi dan kerjasama yang solid dalam rangka mensukseskan program PPK di UMK.

\section{DAFTAR PUSTAKA}

Fahlia, \& Mulyani, E. (2018). Motivasi berwirausaha mahasiswa Pendidikan Ekonomi. Socia: Jurnal Ilmu-Ilmu Sosial, 15(2), 204-211. https://doi.org/10.21831/socia.v15i2.22679

Fatharani, A., Mulyadi, H., \& Widjadjanta, B. (2019). Peranan Motivasi Berwirausaha dan Lingkungan Keluarga Dalam Meningkatkan Sikap Kewirausahaan Mahasiswi. Journal of Business Management Education (JBME), 4(2), 1-9. https://doi.org/10.17509/jbme.v4i2.16394

Fitrihana, N., Jerusalem, M. A., \& Nurseto, T. (2014). Upaya Penumbuhan Karakter Berorientasi Tindakan Melalui Model Pendampingan Bisnis Mahasiswa Berbasis Teknik Coaching. Jurnal Pendidikan Karakter, 5(1), 35-47. https://doi.org/10.21831/jpk.v0i2.2175

Gaffar, V., \& Hendrayati, H. (2019). Faktor kunci kesuksesan studentpreneur. IMAGE: Jurnal Riset Manajemen, 8(2), 77-86.. https://doi.org/10.17509/image.v7i2.22240

Hisrich, R. , \& Peters, Michael, P. (1998). Entrepreneurship. Irwin.

Krisdayanti, \& Trisiana, A. (2019). Program SGK sebagai upaya pembentukan karakter yang kreatif dan berbudaya berbudi luhur di Kadipiro Surakarta. Journal of Community Service, 1(2), 152-164. http://dx.doi.org/10.30659/ijocs.1.2.152-164

Meredith, G. . (2002). Kewirausahaan: Teori dan Praktek. PPM.

Popp, A., \& Holt, R. (2013). The presence of entrepreneurial opportunity. Business History, 55(1). https://doi.org/10.1080/00076791.2012.687539

Siregar, B. P. (2018). Jumlah Pengusaha Indonesia Masih Tertinggal Dari Singapura. Warta Ekonomi. https://www.wartaekonomi.co.id/read204928/jumlah-pengusaha-indonesiamasih-tertinggal-dari-singapura.html

Suarmawan, K. A., Suharsono, N., \& Suwena, K. R. (2016). Analisis Faktor-Faktor yang Mempengaruhi Keberhasilan Usaha Mikro dan Kecil (Studi pada Usaha Kerajinan Ingka di Desa Bulian, Kec. Kubutambahan). Jurnal Pendidikan Ekonomi Undiksha, 5(1), 1-10. http://dx.doi.org/10.23887/jjpe.v5i1

Suryana. (2013). Kewirausahaan (Kiat dan Proses Menuju Sukses). Salemba Empat.

Suryaningtyas, D. (2004). Membentuk Karakter Wirausahawan yang Tangguh dan Kreatif. Jurnal Ekonomi Dan Kewirausahaan, http://ejurnal.unisri.ac.id/index.php/Ekonomi/article/viewFile/164/132 
Indonesian Journal of Community Services

Volume 3, No. 2, November 2021

http://jurnal.unissula.ac.id/index.php/ijocs

DOI: http://dx.doi.org/10.30659/ijocs.3.2.126-134

Yanti, Ap. (2019). Pengaruh pendidikan kewirausahaan, self afficacy, locus of control dan karakter wirausaha terhadap minat berwirausaha. Maneggio, 2(2). http://jurnal.umsu.ac.id/index.php/MANEGGIO/article/view/3774/3941 